\title{
The Development and Application of the Replaceable Triangle Track Wheel
}

\author{
Xiaodong Zhao, Xihui Mu, Haoliang Guo, Zihan Zhao \\ Shi jia zhuang new technology application insitute, Shijiazhuang 050000 P. R. China
}

\begin{abstract}
This paper first introduces the structure of the track wheel, and according to a number of classification criteria for the classification of the track wheel; Then summed up its low weight, low shock, low noise, low grounding pressure, high flexible, high speed, quickly changeable and other unique advantages; Finally, summarized the current research and application status of the track wheel and put forward the existing problems and future development trend.
\end{abstract}

Keywords: Triangle track wheel; Development; Application.

\section{Introduction}

The triangle track wheel can be changed to be a new technology in 1990s. It is a new type of walking mechanism which combines the advantages of the traditional tire and the whole track.It can be in do not modify or rarely modified vehicles under the premise, as a direct replacement for vehicle tire, improve vehicle ground area, reduce vehicle ground pressure, enhance the vehicle traction performance, so as to improve the vehicle's off-road capability, to expand the scope of application of the vehicle and the small vibration, low noise, comfortable good.At present, in foreign countries have been widely used in military, agriculture and construction machinery, in the country also have a number of manufacturers and institutions to introduce and research the technology.

\section{The structure and classification of the replaceable triangle track wheel}

Replaceable triangle track wheel made of rubber crawler and wheel structure is composed of two parts, the specific structure as shown in figure 1.The rubber crawler mainly includes three parts, the external tooth, the belt base and the internal tooth, and has the characteristics of longitudinal compliance, lateral stiffness, small mass and flexible rotation, can reduce the pressure on the ground, improve the ability of all kinds of complex terrain.

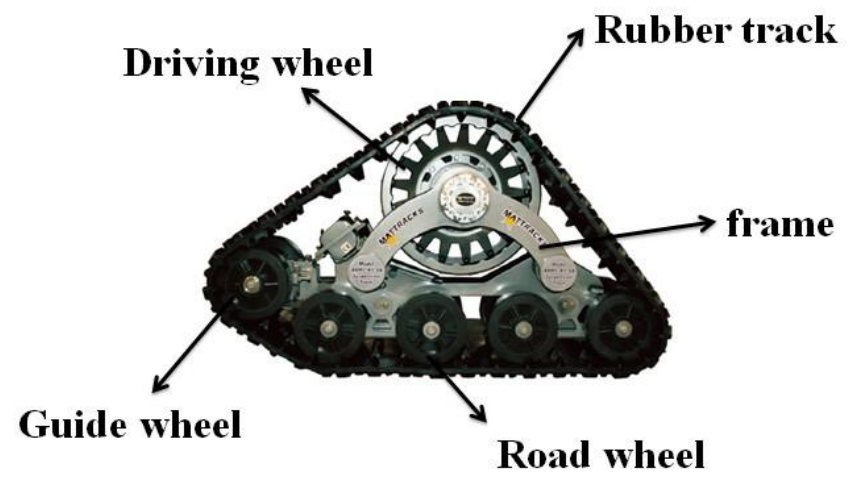

Fig. 1 The structure diagram of the replaceable triangle track wheel

Train structure generally consists of a driving wheel, frame, wheel, guide wheel group and anti flip institutions.According to the structure need, the driving wheel is generally located on the top of the triangle track wheel, and the driving gear is engaged with the driving angle of the rubber track to reach the goal of driving the track;frame is the main structure of the gear train structure and bearing components, used to maintain the triangle track wheel structure, and provide the location for installation of other components; the load wheel group is at the bottom of the triangle track wheel, which bears the load of the track wheel; the guide wheel is generally located at one end or both ends of the triangle track wheel, and is generally responsible for the direction and the direction of the track 
wheel;According to the actual layout of the track wheel, the position of the anti overturning mechanism is generally arranged, which is mainly used for preventing the whole rotation of the track wheel during the running process of the vehicle.

Since the triangle track wheel can be replaced, it has developed and designed many kinds of products, but it has been short of a unified classification method, and it is usually classified according to various standards.According to the different track wheel and vehicle assembly method, it can be divided into two types, the integral and the separate type;according to whether the crawler wheel can drive autonomously, it can be divided into two types, the driving type and the driven type;according to the different track wheel drive mode, it can be divided into two kinds of wheel gear type and wheel hole type;according to the different forms of crawler wheel frame support, can be divided into the cantilever support type and intermediate support type;according to the size of the track wheel bearing, it can be divided into three kinds of light, heavy and super light.

\section{The advantages of the replaceable triangle track wheel}

The replaceable triangle track wheel integrates the traditional tire and the overall track of many advantages, but also overcome many of the shortcomings of the two, formed its own unique advantages.

(1)Compared with the overall type track, the structure of the triangular track wheel is more light and convenient, can quickly replace the tire of the vehicle, $45 \mathrm{~min}$ generally need to be able to complete the four round of wheeled vehicles to complete the replacement of four tires. Vibration and noise generated in contact with the ground and also significantly decreased. The comfort is improved, reduces the labor intensity of the operator, significantly reduced the damage on the ground.Driving on the road slope and bumpy road, the replaceable triangle track wheel has higher stability and passing ability.

(2)Compared with the traditional tire, the ground area of the triangle track wheel is larger, and the ground pressure is lower than that of the traditional tire,its grounding specific pressure only $0.35 \mathrm{~kg} / \mathrm{cm} 2$, traditional tire grounding than the pressure $1 / 25-1 / 20$, only the human foot ground contact pressure of 1 / 6-1/4,improve the traction performance of the vehicle,allows vehicles to pass through the beach, swamps, beaches and snow and other harsh terrain,quickly improves the ability of the traditional wheeled vehicles.

\section{Research and application status of the replaceable triangle track wheel}

The replaceable triangle track wheel since the rise of the 20 world in 90s, after more than 20 years of development, it has made great progress.More famous foreign companies have MATTRACKS, SOUCY and other companies, have formed a standardized series of related products.Domestic development is relatively slow, at present most of the units are in the initial design and development stage.

Due to its unique advantages, it has been widely used in the fields of agriculture, military, industry and commerce.

Agricultural field

Due to the large ground area of the triangle track wheel,low grounding pressure and low weight,effectively solves the problem of the agricultural machinery in the soft terrain, such as the paddy field and the sandy land, and protect the farmland soil.At present, mainly used in seeder,harvester,forklift and agricultural machinery.

Military field

Due to the replaceable triangle track wheel replacement is simple, can quickly improve the wheeled vehicle off-road mobility, it is widely used in the relevant security and operational equipment,used in the snow, sand, beaches and marshes and other harsh terrain, to improve the army's ability to combat all terrain.

Industrial field 
The replaceable triangle track wheel in the industrial application is very wide, mainly used for a variety of construction machinery in the complex operating environment to complete the job.Including a variety of post disaster repair, large mining and operating machinery, excavating machinery, loading machine and forklift.

Business field

In the business field, mainly used in the beach and ski resorts and other places with soft ground related tourism, used to achieve the relevant tourist site maintenance, related to the tourism site of garbage clean-up and work services and other functions.

\section{The development trend of the replaceable triangle track wheel}

The replaceable triangle track wheel as a new technology, is still in the initial stage of development, although it has also made some achievements, the formation of a number of related products, there are still a lot of problems,there are still a lot of gaps in the design of the triangle track wheel, and the design of many related structures still have great room for improvement.Therefore, the future development trend of the triangle track wheel can be replaced mainly in the following aspects: (1) In the rubber track, the rubber track of the current light track wheel has been relatively mature, but the rubber track technology is still relatively lack, Therefore, the rubber track technology can be improved in terms of materials, processes and structures to meet the requirements of the heavy track wheels.(2) In the bearing capacity, the current load capacity of the triangular track wheel is relatively small,needs to improve the basic frame, wheels and tensioner other train structure to improve crawler wheel loading capability,to meet the needs of large military equipment and heavy construction vehicles.(3) Structural optimization of the triangle track wheel to make the structure more stable and portable.(4) Damping device design, the design effect is more obvious weight loss device.(5) To strengthen the collaborative development of existing wheeled vehicles, expand the application range of the track wheel technology, and promote the standardization and serialization process of the track wheel.

\section{Conclusion}

The replaceable triangle track wheel, which is a new type of application technology of rubber track, and is a new type of walking mechanism combined with the advantages of the traditional tire and the whole track.In this paper, the structure of the replaceable triangle track wheel is introduced, and according to the structure characteristics of the track wheel and the driving mode, the track wheel is classified.Compared with the traditional tire and the whole track, the unique advantages of the track wheel are summarized.Summarized the development trend of the future. As a kind of new technology, it will have broad prospects for development and application prospects.

\section{References}

[1]. Brown H J,Cruse R.M,Erbach D.C,et al. Tractive device effects on soil physical properties.Soil and Tillage Research.VOL.22(1992) NO 1 p 41-53

[2]. Watanabe K,Kitano M,Takano K,et al.Study on rolling resistance of rubber track.Transactions of the Japan Society of Mechanical Engineers. VOL.62(1996) NO603 p 4212-4217I

[3]. Sheridan G J.A comparison of rubber-tyred and steel-tracked skidders on forest soil physical properties.Australian Journal of Soil Research.VOL41(2003) NO6 p 1063-1075 